\title{
Association of surgical approach and prolonged opioid prescriptions in patients undergoing major pelvic cancer procedures
}

Marieke J. Krimphove ${ }^{1,2}$, Xi Chen', Maya Marchese', David F. Friedlander ${ }^{1}$, Adam C. Fields $^{3}$, Lina Roa ${ }^{4}$, Daniel Pucheril ${ }^{1}$, Adam S. Kibel ${ }^{1}$, Nelya Melnitchouk ${ }^{5}$, Richard D. Urmann', Luis A. Kluth², Prokar Dasgupta ${ }^{7}$ and Quoc-Dien Trinh $^{1 *}$ (D)

\begin{abstract}
Background: The rise in deaths attributed to opioid drugs has become a major public health problem in the United States and in the world. Minimally invasive surgery (MIS) is associated with a faster postoperative recovery and our aim was to investigate if the use of MIS was associated with lower odds of prolonged opioid prescriptions after major procedures.

Methods: Retrospective study using the IBM Watson Health Marketscan ${ }^{\oplus}$ Commerical Claims and Encounters Database investigating opioid-naïve cancer patients aged 18-64 who underwent open versus MIS radical prostatectomy (RP), partial colectomy (PC) or hysterectomy (HYS) from 2012 to 2017. Propensity weighted logistic regression analyses were used to estimate the independent effect of surgical approach on prolonged opioid prescriptions, defined as prescriptions within 91-180 days of surgery.

Results: Overall, 6838 patients underwent RP (MIS 85.5\%), 4480 patients underwent PC (MIS 61.6\%) and 1620 patients underwent HYS (MIS 41.8\%). Approximately 70-80\% of all patients had perioperative opioid prescriptions. In the weighted model, patients undergoing MIS were significantly less likely to have prolonged opioid prescriptions in all three surgery types (Odds Ratio [OR] 0.737, 95\% Confidence Interval [CI] 0.595-0.914, $p=0.006$; OR $0.728,95 \% \mathrm{Cl} 0.600-0.882, p=0.001$; OR $0.655,95 \% \mathrm{Cl} 0.466-0.920, p=0.015$, respectively).

Conclusion: The use of the MIS was associated with lower odds of prolonged opioid prescription in all procedures examined. While additional studies such as clinical trials are needed for further confirmation, our findings need to be considered for patient counseling as postoperative differences between approaches do exist.
\end{abstract}

Keywords: Surgical approach, Minimally invasive surgery, Opioids

\footnotetext{
* Correspondence: qtrinh@bwh.harvard.edu

'Division of Urological Surgery and Center for Surgery and Public Health, Brigham and Women's Hospital, Harvard Medical School, 45 Francis St., ASB II-3, Boston, MA 02115, USA

Full list of author information is available at the end of the article
}

(c) The Author(s). 2020 Open Access This article is licensed under a Creative Commons Attribution 4.0 International License, which permits use, sharing, adaptation, distribution and reproduction in any medium or format, as long as you give appropriate credit to the original author(s) and the source, provide a link to the Creative Commons licence, and indicate if changes were made. The images or other third party material in this article are included in the article's Creative Commons licence, unless indicated otherwise in a credit line to the material. If material is not included in the article's Creative Commons licence and your intended use is not permitted by statutory regulation or exceeds the permitted use, you will need to obtain permission directly from the copyright holder. To view a copy of this licence, visit http://creativecommons.org/licenses/by/4.0/ The Creative Commons Public Domain Dedication waiver (http://creativecommons.org/publicdomain/zero/1.0/) applies to the data made available in this article, unless otherwise stated in a credit line to the data. 


\section{Background}

The United States is currently in the midst of a major opioid epidemic [1], with drug overdose supplanting motor vehicle collisions as the number one cause of accidental death [2]. The National Institute on Drug Abuse recently disclosed that more than 70,000 drug overdose deaths were registered in 2017 [2]. The rate of drug overdose deaths involving synthetic opioids other than methadone increased by $88 \%$ per year from 2013 to 2016 [2, 3]. Explanations for these trends include poor access to prevention, treatment, and recovery programs as well as more frequent opioid prescriptions [4, 5].

Major surgery may induce opioid use disorder in certain individuals as pain medication is prescribed on a regular basis after such procedures [6]. Expectations for no pain after surgery, as well as aggressive marketing to physicians from drug companies have led to increased use of opioids in the perioperative setting. For example, opioid prescriptions increased significantly from 2004 to 2014 in women undergoing hysterectomy for benign indications, even though less invasive techniques have emerged in recent years [7].

Minimally invasive surgery (MIS) is associated with certain perioperative benefits, such as decreased operative blood loss, shorter operation time, and length of stay, all of which have resulted in shorter recovery times following surgery $[8,9]$. While prior research has focused on the perioperative period, little is known about intermediate term possible benefits MIS has on patients' recovery.

Therefore, we sought to investigate differences in prolonged opioid prescription following MIS versus open surgery in common major cancer procedures. We hypothesized that the odds of prolonged opioid prescription is lower in patients undergoing MIS.

\section{Methods}

\section{Data source}

We queried the IBM Watson Health (formerly Truven Health Analytics) Marketscan ${ }^{\oplus}$ Commercial Claims and Encounters Database, which contains enrollment and healthcare (medical and drug) claims of millions of employees and their dependents who are covered annually under diverse health plans offered by medium or large sized firms. There are distinct data collected for inpatient, outpatient, emergency department, and outpatient prescription drug claims, all of which are linked by a unique patient identifier. From 2012 to 2017, the database contained de-identified claims for 1.87 million enrollees, $53 \%$ covered by self-insured employers and $47 \%$ covered by health plans.

The Marketscan ${ }^{\oplus}$ database only captures prescriptions filled at outpatient pharmacies and does not capture prescriptions filled within the hospital facility. Thus, inpatient opioid use could not be included in postoperative opioid use. Pharmacy claims data include the fill date, quantity supplied, and number of days supplied.

\section{Patient selection}

The study cohort included patients aged 18-64 years of age, who underwent radical prostatectomy for prostate cancer, partial colectomy for colon cancer, or hysterectomy for uterine cancer between January 2012 and December 2017 (Additional file 1). Patients over the age of 64 were not included given their Medicare eligibility, a national health insurance program for elderly and disabled persons. The three procedures were selected based on both the public health significance with regard to overall volume and the contemporary prevalence of both open and MIS approaches for the procedure. If there were multiple claims for a given surgery, the earliest date was considered as the index surgical date. We analyzed individuals who were continuously enrolled for a period of at least 1 year prior to surgery up until 180 days after surgery. Patients with incomplete demographic data were excluded.

We only included opioid naïve individuals, defined as patients with no opioid prescription within 1 year to 31 days before surgery and with no history of opioid use disorder (ICD-9 code 304.00-304.03; 305.5-305.53, and ICD-10 codes F 11.1x, F11.2x). Opioid prescriptions within 30 days before surgery were considered surgeryrelated and prescribed for postoperative pain management, as previously described (Fig. 1) [10, 11].

\section{Exposure of interest}

The exposure of interest was surgical approach defined as open or MIS, including robotic surgery, of one of three major procedures: radical prostatectomy, partial colectomy, and hysterectomy.

\section{Outcomes}

Consistent with prior conventions, our main outcome of interest was prolonged opioid prescription, defined as prescriptions filled within 91 to 180 days from surgery in patients who had also filled at least one prescription within the perioperative period, 30 days prior to 2 weeks after surgery $[6,10,12]$. This time period was chosen given that opioid use disorder is defined by the Centers for Disease Control and Prevention as opioid use for more than 3 months (91+ days).

\section{Covariates}

Covariates included age $(<34,35-44,45-54,55-64)$, sex, year of surgery, Elixhauser Comorbidity Index $(0,1$, $\geq 2$ ), US Census Region (Northeast, North Central, South, West, Unknown), Urban vs. Rural residence, colostomy (only for partial colectomy), low anterior resection (only for partial colectomy) and health plan type 


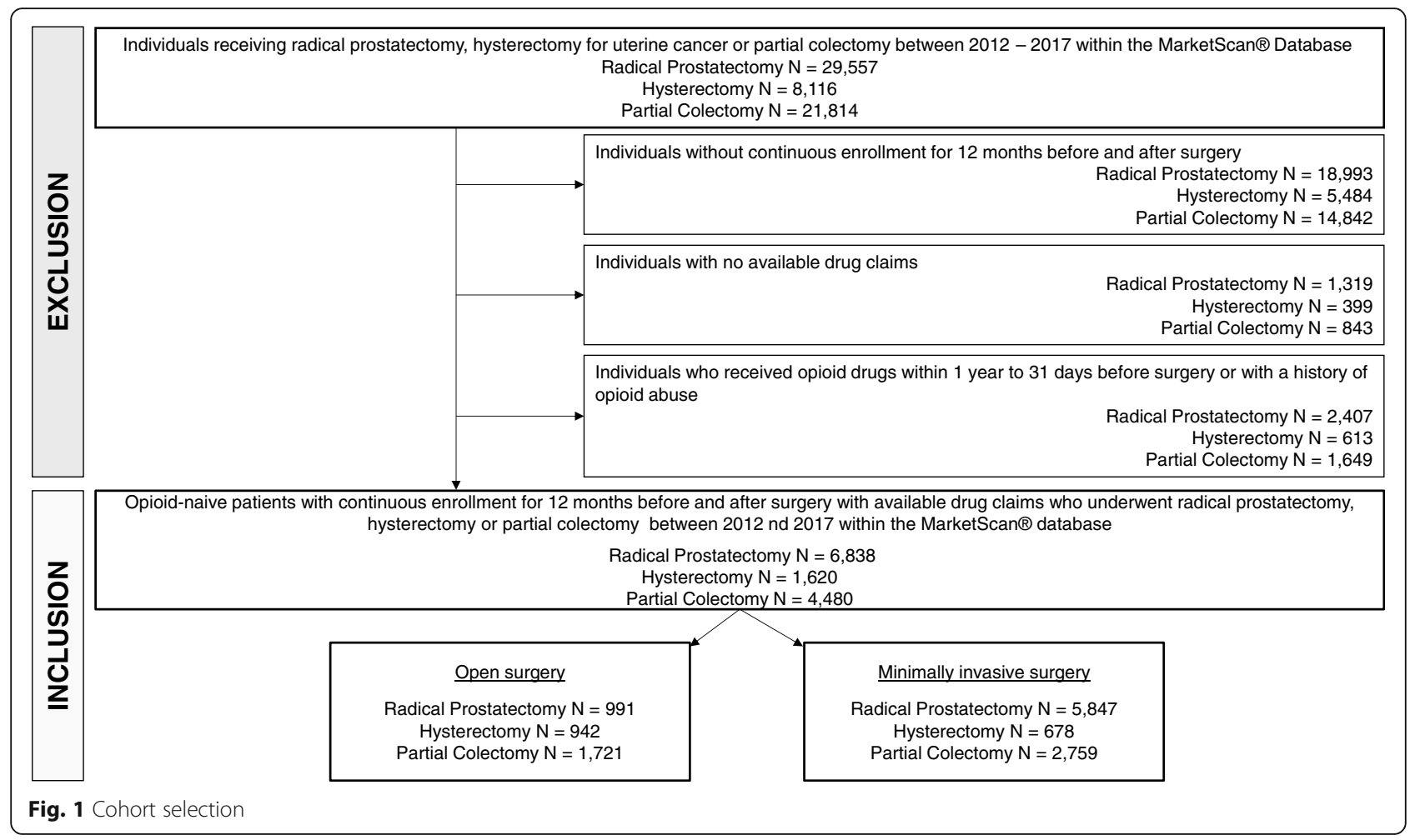

(less restrictive, more restrictive). Furthermore, we accounted for chronic opioid use risk factors for as described in literature $[10,12]$. In brief, we examined if a patient had a claim with an ICD-9 code for depression, substance abuse other than opioids, and other mental health disorders (e.g. schizophrenia, mood disorders, etc.) (Additional file 2).

\section{Statistical analyses}

Patient characteristics were compared by surgical approach (open vs. MIS) using t-tests for continuous variables or chi-square tests for categorical variables. We conducted an inverse probability of treatment weighted (IPTW) propensity score analysis to statistically pseudorandomize the cohorts [13]. Therefore, we fit a logistic regression model and treatments were weighed by the inverse of their propensity score, while controls were weighted by the inverse of (1-propensity score). We controlled for all variables described above including the risk factors for opioid abuse, and year of diagnosis. An IPTW-weighted logistic regression was then used to assess the association between open versus MIS and prolonged opioid prescriptions.

All statistical analyses were performed using SAS 9.4 (SAS Institute Inc., SAS Campus Drive, Cary, North Carolina 27513, USA), a two-sided significance level was set at $p<0.05$. Prior to performing this study we obtained an institutional review board waiver from Brigham and Women's Hospital.

\section{Results}

\section{Baseline characteristics}

Table 1 summarizes the unweighted baseline characteristics of all patients who underwent one of the three procedures. In total, 6838 patients underwent radical prostatectomy, 4480 patients underwent partial colectomy, and 1620 patients underwent hysterectomy for uterine cancer. While radical prostatectomy and partial colectomy were performed in a MIS fashion for the majority of patients $(85.5$, and $61.6 \%$, respectively), hysterectomy was mostly performed using the open approach (58.2\%). All open procedures were significantly more often performed in southern states (all $p<0.05$ ), open radical prostatectomy and partial colectomy were more often performed in rural areas (18.5\% vs. 14.0 and $20.2 \%$ vs. $14.2 \%$, respectively, both $p<0.05)$. Women undergoing MIS hysterectomy were significantly more often in the oldest age group (58.9 vs. $68.6 \%, p<0.001)$.

\section{Unadjusted perioperative and prolonged opioid prescriptions}

Approximately 70 to $80 \%$ of all patients had at least one perioperative opioid prescription, irrespective of surgery type and surgical approach (Table 1).

Prolonged use was most pronounced in patients who underwent open partial colectomy with $18.2 \%$, followed by open hysterectomy (14.3\%) and MIS partial colectomy (12.1\%). In the unadjusted model, prolonged opioid 
Table 1 Baseline characteristics of opioid-naïve patients undergoing one of the following procedures: prostatectomy, partial colectomy, and hysterectomy between 2012 and 2017 within the Marketscan database

\begin{tabular}{|c|c|c|c|c|c|c|c|c|c|}
\hline \multirow{2}{*}{$\begin{array}{l}\text { Procedure } \rightarrow \\
\text { Co-variates } \downarrow\end{array}$} & \multicolumn{3}{|c|}{ Prostatectomy $N=6838$} & \multicolumn{3}{|c|}{ Partial colectomy $N=4480$} & \multicolumn{3}{|c|}{ Hysterectomy $N=1620$} \\
\hline & $\begin{array}{l}\text { open } 991 \\
(14.5 \%)\end{array}$ & $\begin{array}{l}\text { MIS } 5847 \\
(85.5 \%)\end{array}$ & $p$-value & $\begin{array}{l}\text { open } 1721 \\
(38.4)\end{array}$ & $\begin{array}{l}\text { MIS } 2759 \\
(61.6)\end{array}$ & $p$-value & $\begin{array}{l}\text { open } 942 \\
(58.2)\end{array}$ & $\begin{array}{l}\text { MIS } 678 \\
(41.9)\end{array}$ & $p$-value \\
\hline Age & 0.124 & & & 0.028 & & & $<0.001$ & & \\
\hline $18-34$ & 0 & $1(0.0)$ & & $33(1.9)$ & $41(1.5)$ & & $11(1.2)$ & $10(1.5)$ & \\
\hline $35-44$ & $15(1.5)$ & $85(1.5)$ & & $198(11.5)$ & $235(8.5)$ & & $80(8.5)$ & $39(5.8)$ & \\
\hline $45-54$ & $220(22.2)$ & $1504(25.7)$ & & $600(34.9)$ & $1052(38.1)$ & & $296(31.4)$ & $164(24.2)$ & \\
\hline $55-64$ & $756(76.3)$ & $4257(72.8)$ & & $890(51.7)$ & $1431(51.8)$ & & $555(58.9)$ & 465 (68.6) & \\
\hline Gender & & & & 0.718 & & & & & \\
\hline Male & & & & $865(50.3)$ & $1402(50.8)$ & & & & \\
\hline female & & & & $856(49.7)$ & $1357(49.2)$ & & & & \\
\hline Elixhauser comorbidity & 0.462 & & & $<0.001$ & & & 0.252 & & \\
\hline 0 & $204(20.6)$ & $1268(21.7)$ & & $184(10.7)$ & $344(12.5)$ & & $111(11.8)$ & $100(14.8)$ & \\
\hline 1 & $346(34.9)$ & $1929(31.0)$ & & $369(21.4)$ & $658(23.9)$ & & $206(21.9)$ & $139(20.5)$ & \\
\hline$\geq 2$ & $441(44.5)$ & $2650(45.3)$ & & $1168(67.9)$ & $1757(63.7)$ & & $625(66.4)$ & $439(65.8)$ & \\
\hline Geographic region & $<0.001$ & & & $<0.001$ & & & $<0.001$ & & \\
\hline Northeast & $183(18.5)$ & $1225(21.0)$ & & $324(18.8)$ & $563(20.4)$ & & $218(23.1)$ & $170(25.1)$ & \\
\hline North central & $193(19.5)$ & $1521(26.0)$ & & $389(22.6)$ & $567(22.6)$ & & $221(23.5)$ & $159(23.5)$ & \\
\hline South & $459(46.3)$ & $2234(38.2)$ & & $797(46.3)$ & $1202(43.6)$ & & $363(38.5)$ & $175(25.8)$ & \\
\hline West & $145(14.6)$ & $830(14.2)$ & & $195(11.3)$ & $414(15.0)$ & & $132(14.0)$ & $170(25.1)$ & \\
\hline Unknown & $11(1.1)$ & $37(0.6)$ & & $16(0.9)$ & $13(0.4)$ & & $8(0.9)$ & $4(0.6)$ & \\
\hline Residence & $<0.001$ & & & $<0.001$ & & & 0.456 & & \\
\hline Rural & $183(18.5)$ & $819(14.0)$ & & $347(20.2)$ & $392(14.2)$ & & $133(14.1)$ & $87(12.8)$ & \\
\hline Urban & $808(81.5)$ & $5028(86.0)$ & & $1374(79.8)$ & 2367 (85.8) & & 809 (85.9) & $591(87.2)$ & \\
\hline Health plan & 0.521 & & & 0.788 & & & 0.831 & & \\
\hline Less restrictive & $643(64.9)$ & 3855 (65.9) & & $1142(66.4)$ & $1820(66.0)$ & & $626(66.5)$ & $454(67.0)$ & \\
\hline More restrictive & $348(35.1)$ & $1992(34.1)$ & & $579(33.6)$ & $939(34.0)$ & & 316 (33.6) & $224(30.4)$ & \\
\hline Colostomy & & & & $233(13.5)$ & $93(3.4)$ & $<0.001$ & & & \\
\hline Low anterior resection & & & & $360(20.9)$ & $764(27.7)$ & $<0.001$ & & & \\
\hline \multicolumn{10}{|l|}{ Mental health disorders } \\
\hline Depression & $51(5.1)$ & $319(5.5)$ & 0.691 & $103(6.0)$ & $193(7.0)$ & 0.185 & $62(6.6)$ & $57(8.4)$ & 0.165 \\
\hline Substance abuse & $42(4.2)$ & $252(4.3)$ & 0.918 & $76(4.4)$ & $119(4.3)$ & 0.870 & $22(2.3)$ & $11(1.6)$ & 0.316 \\
\hline Other & $30(3.0)$ & $226(3.9)$ & 0.199 & $75(4.3)$ & $107(3.9)$ & 0.429 & $41(4.4)$ & $28(4.1)$ & 0.827 \\
\hline \multicolumn{10}{|l|}{ Opioid prescriptions } \\
\hline Perioperative & $776(78.3)$ & $4680(80.0)$ & 0.208 & $1223(71.1)$ & $1980(71.8)$ & 0.613 & $761(80.8)$ & $536(79.1)$ & 0.390 \\
\hline Prolonged & $65(8.4)$ & $262(5.6)$ & 0.004 & $223(18.2)$ & $240(12.1)$ & $<0.001$ & $109(14.3)$ & $50(9.3)$ & 0.007 \\
\hline
\end{tabular}

Abbreviation: MIS minimally invasive surgery

prescriptions occurred significantly less often in individuals undergoing MIS for all three procedure groups. (all $p<0.05)$.

\section{Adjusted prolonged opioid prescriptions}

In the IPTW logistic regression model, relative to patients undergoing conventional open surgery, patients undergoing MIS for all three procedures were less likely to have prolonged opioid prescriptions: radical prostatectomy,
(Odds ratio [OR] 0.737, 95\% Confidence Interval [CI] 0.595 to $0.914, p=0.006$ ), partial colectomy (OR 0.728 , $95 \%$ CI 0.600 to $0.882, p=0.001$ ), and hysterectomy (OR $0.65595 \%$ CI 0.466 to $0.920, p=0.015$ ) (Table 2).

\section{Discussion}

Against the background of increasing death rates from opioid use, opioid prescriptions following major surgical procedures are perceived as possible precipitating factors 
Table 2 IPTW-weighted logistic regression predicting prolonged opioid prescription in opioid-naive patients undergoing radical prostatectomy, partial colectomy or hysterectomy

\begin{tabular}{|c|c|c|c|c|c|c|c|c|c|}
\hline & \multicolumn{3}{|c|}{ Radical prostatectomy } & \multicolumn{3}{|c|}{ Partial colectomy } & \multicolumn{3}{|c|}{ Hysterectomy } \\
\hline & OR & $95 \%-\mathrm{Cl}$ & $p$-value & OR & $95 \%-\mathrm{Cl}$ & $p$-value & OR & $95 \%-\mathrm{Cl}$ & $p$-value \\
\hline Open & Ref. & & & Ref. & & & Ref. & & \\
\hline MIS & 0.737 & $0.595-0.914$ & 0.006 & 0.728 & $0.600-0.882$ & 0.001 & 0.655 & $0.466-0.920$ & 0.015 \\
\hline
\end{tabular}

Weighted for: Year, Age, Sex, Elixhauser Comorbidity, Geographic region, Residence, Health Plan, Mental Health Disorders, Colostomy, Low Anterior Resection Abbreviations: MIS minimally invasive surgery, OR Odds ratio, 95\%-CI 95\% Confidence Interval, Ref. Reference

of opioid misuse and abuse [14]. Patients undergoing surgical procedures often receive opioid prescriptions with unclear instructions and expectations. Moreover, prescriptions are often renewed when faced with patient complaints, with little investigation into the cause of the symptoms and the appropriateness of the opioid medication for the problem [15]. Our study sought to investigate differences in prolonged opioid prescriptions following open and MIS approaches for radical prostatectomy, partial colectomy and hysterectomy adding a new perspective to a growing body of work, investigating opioid prescription pattern $[11,16]$.

Prolonged prescription use was less common after minimally invasive radical prostatectomy partial colectomy, and hysterectomy relative to the respective open approaches. To our knowledge, this is the first study to demonstrate the intermediate-term benefit of MIS with regard to opioid use. Though novel, our findings are consistent with previous findings of decreased perioperative analgesia requirements, and quicker recuperation afforded by MIS $[17,18]$. Therefore, the increased perioperative costs of MIS, including robotic surgery may be offset by long-term advantages such as quicker return to work and decreased opioid utilization $[19,20]$.

From a practical perspective, our findings are important to consider when more than half of patients who receive 90 days of continuous opioid therapy will remain on opioids years later [21]. Similarly, in opioid naïve patients, those with opioid prescriptions within 7 days of surgery are $44 \%$ more likely to become long term opioid users [22]. Further, data from trauma surgery has demonstrated that up to $8.8 \%$ of patients continue using opioids 6 months after surgery [23-25]. While the relationship between early opioid use and long-term addiction is still poorly understood, one possible explanation may be early desensitization of opioid receptors after acute opioid administration [26] requiring more opioids in order to achieve the same level of pain relief (i.e. acute opioid tolerance and hyperalgesia). This in turn leads to adaptive tolerance of opioid receptors, feeding the downward spiral to opioid addiction. Additionally, there are other neurobiological [27], psychological [28, 29], and personal factors [30] involved in the complex interaction that results in opioid use disorder. Nonetheless, the probability of long-term opioid use increases most sharply in the first days of therapy [31]; thus, to prevent long-term opioid use it is crucial to transition to less addictive analgesic alternatives early in the post-operative course.

Of note, we found that 70 to $80 \%$ of all patients - irrespective of site and type of surgical approach - receive perioperative opioid prescriptions. Opioids are effective drugs in treating acute pain, nevertheless opioids are highly addictive and even short-term use can result in unintentional prolonged use with a risk of abuse and dependence [32]. Similar results were seen in patients who undergo low-risk surgery. Wunsch et al. found that within 7 days from surgery, $80 \%$ filled a prescription for any opioid - with an increasing trend over time [33]. Postoperative pain is common in patients undergoing major surgical procedures and pain management is most crucial in terms of preventing chronic pain with associated decrease of quality of life [34]. In 2016, a Clinical Practice Guideline from the American Pain Society, the American Society of Regional Anesthesia and Pain Medicine, and the American Society of Anesthesiologists' Committee on Regional Anesthesia advised that safe and effective postoperative pain management should be tailored to the individual and the surgical procedure involved [35]. For example, following radical prostatectomy, many advocate the primary use of non-opioid analgesics and/or regional analgesic techniques with opioids utilized only when necessary [36]. However, despite efforts to curtail opioid over-utilization, postsurgical pain management remains poorly understood. Patel et al. found that in patients undergoing radical prostatectomy, $77 \%$ of opioids prescribed were unused, with $84 \%$ of patients using less than half of their prescription [37]. It is possible, that physicians routinely prescribe opioid drugs following surgery, without taking into account the actual patient's need.

Our study has several limitations. First, the retrospective design leaves room for unmeasured confounding. For example, we cannot account for surgical complexity cases selected for the open approach may be more technically complex and at risk for complications than MIS cases. Second, we looked at prescription rates following surgery which may be different from the patient's actual consumption of opioid drugs. More than $50 \%$ of patients are using less than half of the prescribed opioids [37, 38]. However, many opioid drugs are in uncontrolled circulation 
lacking medical monitoring. In theory, these overprescriptions may be diverted to other individuals in the setting of illegal resale. Regardless, Howard et al. found that prolonged prescription is correlated with increased consumption [39]. Third, we were not able to account for the effect of cancer stage on opioid prescriptions as this information was not available in the database. Patients presenting with more advanced disease at presentation may be preferentially managed with open surgery. Such cases are more at risk for progression and metastasis, which may require opioid use for palliative pain control. What's more, the database does not contain information on the incision made during open surgery which might impact postoperative pain (e.g. pfannenstiel vs. midline incision). Fourth, data mostly come from large employers and medium and small firms may be underrepresented [40]. Moreover, this analysis excludes under- and un-insured individuals, and therefore is not representative of the US population as a whole. Fifth, we did not account for different postoperative management pathways including the use of enhanced recovery after surgery that may explain differences between prolonged opioid prescriptions rather than the surgical approach itself [41].

\section{Conclusion}

The use of the MIS was associated with lower odds of prolonged opioid prescription in all procedures examined. While additional studies such as clinical trials are needed for further confirmation, our findings need to be considered for patient counseling as postoperative differences between approaches do exist.

\section{Supplementary information}

Supplementary information accompanies this paper at https://doi.org/10. 1186/s12893-020-00879-5.

Additional file 1. ICD-9, ICD-10 and CPT codes for disease states and procedures

Additional file 2 . ICD-9 and ICD-10 codes for risk factors of opioid use disorder

\section{Abbreviations}

Cl: Confidence interval; HYS: Hysterectomy; IPTW: Inverse probability of treatment weighted; MIS: Minimally invasive surgery; OR: Odds ratio; PC: Partial colectomy; RP: Radical prostatectomy

\footnotetext{
Acknowledgements

Quoc-Dien Trinh is supported by the Brigham Research Institute Fund to Sustain Research Excellence, the Bruce A. Beal and Robert L. Beal Surgical Fellowship, the Genentech Bio-Oncology Career Development Award from the Conquer Cancer Foundation of the American Society of Clinical Oncology, a Health Services Research pilot test grant from the Defense Health Agency, the Clay Hamlin Young Investigator Award from the Prostate Cancer Foundation and an unrestricted educational grant from the Vattikuti Urology Institute. David F. Friedlander is supported by a National Institutes of Health T32 training grant.
}

\section{Authors' contributions}

The corresponding author attests that all listed authors meet authorship criteria and that no others meeting the criteria have been omitted. All authors have read and approved the manuscript. MJK: Conceptualization, formal analysis, investigation, methodology, visualization, writing - original draft, and writing - review and editing. XC: Conceptualization, formal analysis, investigation, methodology, visualization, writing - original draft, and writing - review and editing. MM: Conceptualization, formal analysis, investigation, methodology, visualization, and writing - review and editing. DFF:

Conceptualization, writing - original draft, and writing - review and editing, supervision. ACF: Conceptualization, methodology, and writing - review and editing. LR: Conceptualization, methodology, and writing - review and editing. DP: Conceptualization, methodology, writing - original draft, and writing - review and editing, supervision. ASK: Supervision, writing - review and editing. NM: Supervision, writing - review and editing. RDU: Methodology, supervision, writing - review and editing. LAK: Supervision, writing, review and editing. PD: Supervision, writing, review and editing. QDT: Conceptualization, methodology, investigation, visualization, supervision, and writing - review and editing.

\section{Funding}

This study was funded by Intuitive Surgical through an educational grant examining the long-term impacts of minimally invasive surgery. The funders of the study had no role in study design, data collection, data analysis, data interpretation, or writing of the report. The corresponding author had full access to all the data in the study and had final responsibility for the decision to submit for publication.

\section{Availability of data and materials}

The data of this study is from IBM Marketscan ${ }^{\oplus}$ and we do not have the authority to share.

\section{Ethics approval and consent to participate}

Prior to performing this study we obtained an institutional review board waiver from Brigham and Women's Hospital. We received permission to use the Marketscan ${ }^{\circledast}$ data. IBM is the owner of the data.

This research was done without patient involvement. Patients were not invited to comment on the study design and were not consulted to develop patient relevant outcomes or interpret the results. Patients were not invited to contribute to the writing or editing of this document for readability or accuracy.

\section{Consent for publication}

Not applicable.

\section{Competing interests}

QDT reports honoraria from Astellas, Bayer, Janssen, Insightec and Intuitive Surgical. ASK reports consulting fees from Janssen, Merck, Pfizer, BristleMeyers Squib, Insightec and Profound. RDU reports consulting fees from Medtronic and Merck. All other authors declare that they have no conflict of interest.

\section{Author details}

${ }^{1}$ Division of Urological Surgery and Center for Surgery and Public Health, Brigham and Women's Hospital, Harvard Medical School, 45 Francis St., ASB II-3, Boston, MA 02115, USA. Department of Urology, University Hospital Frankfurt, Frankfurt, Germany. ${ }^{3}$ Division of General and Gastrointestinal Surgery, Department of Surgery, Brigham and Women's Hospital, Harvard

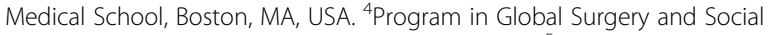
Change, Harvard Medical School, Boston, MA, USA. ${ }^{5}$ Department of Surgery and Center for Surgery and Public Health, Brigham and Women's Hospital, Harvard Medical School, Boston, MA, USA. ${ }^{6}$ Department of Anesthesiology, Perioperative and Pain Medicine, Harvard Medical School, Brigham and Women's Hospital, Boston, MA, USA. 'Department of Urology, King's College London, Guy's and St. Thomas' Hospitals NHS Foundation Trust, Guy's Hospital, London, UK. 
Received: 10 May 2020 Accepted: 23 September 2020

Published online: 14 October 2020

\section{References}

1. Shiels MS, Freedman ND, Thomas D, Berrington de Gonzalez A. TRends in U. S. drug overdose deaths in non-hispanic black, hispanic, and non-hispanic white persons, 2000-2015. Ann Intern Med. 2018;168:453-5.

2. H Hedegaard, AM Minino, M Warner. Drug overdose deaths in the United States, 1999-2017. NCHS Data Brief; 2018. pp. 1-8.

3. Hedegaard H, Warner M, Miniño AM. Drug overdose deaths in the United States, 1999-2016. Washington, D.C.: US Department of Health and Human Services, Centers for Disease Control and Prevention, National Center for Health Statistics; 2017.

4. Blanco C, Iza M, Rodriguez-Fernandez JM, Baca-Garcia E, Wang S, Olfson M. Probability and predictors of treatment-seeking for substance use disorders in the U.S. Drug Alcohol Depend. 2015;149:136-44.

5. Ali MM, Teich JL, Mutter R. Reasons for not seeking substance use disorder treatment: variations by health insurance coverage. J Behav Health Serv Res. 2017:44:63-74.

6. Clarke H, Soneji N, Ko DT, Yun L, Wijeysundera DN. Rates and risk factors for prolonged opioid use after major surgery: population based cohort study. BMJ. 2014;348:g1251.

7. Thompson JC, Komesu YM, Qeadan F, Jeppson PC, Cichowski SB, Rogers RG, et al. Trends in patient procurement of postoperative opioids and route of hysterectomy in the United States from 2004 through 2014. Am J Obstet Gynecol. 2018:219(5):484.e1-484.e11.

8. Ploussard G. Robotic surgery in urology: facts and reality. What are the real advantages of robotic approaches for prostate cancer patients? Curr Opin Urol. 2018:28:153-8.

9. Hic D, Evans SM, Allan CA, Jung JH, Murphy D, Frydenberg M. Laparoscopic and robotic-assisted versus open radical prostatectomy for the treatment of localised prostate cancer. Cochrane Database Syst Rev. 2017;9:CD009625.

10. Johnson SP, Chung KC, Zhong L, Shauver MJ, Engelsbe MJ, Brummett C, et al. Risk of prolonged opioid use among opioid-naive patients following common hand surgery procedures. J Hand Surg [Am]. 2016:41:947-957.e3.

11. Brescia AA, Harrington CA, Mazurek A, Ward S, Lee JSJ, Hu HM, et al. Factors associated with new persistent opioid usage after lung resection. Ann Thorac Surg. 2018;107(2):363-8

12. Marcusa DP, Mann RA, Cron DC, Fillinger BR, Rzepecki AK, Kozlow JH, et al. Prescription opioid use among opioid-naive women undergoing immediate breast reconstruction. Plast Reconstr Surg. 2017;140:1081-90.

13. Cole AP, Trinh QD. Secondary data analysis: techniques for comparing interventions and their limitations. Curr Opin Urol. 2017;27:354-9.

14. Theisen K, Jacobs B, Macleod L, Davies B. The United States opioid epidemic: a review of the surgeon's contribution to it and health policy initiatives. BJU Int. 2018;122:754-9.

15. Von Korff M, Saunders K, Thomas Ray G, Boudreau D, Campbell C, Merrill J, et al. De facto long-term opioid therapy for noncancer pain. Clin J Pain. 2008;24:521-7

16. Sun EC, Darnall BD, Baker LC, Mackey S. Incidence of and risk factors for chronic opioid use among opioid-naive patients in the postoperative period. JAMA Intern Med. Sep 1 2016:176:1286-93.

17. Darr C, Cheufou D, Weinreich G, Hachenberg T, Aigner C, Kampe S. Robotic thoracic surgery results in shorter hospital stay and lower postoperative pain compared to open thoracotomy: a matched pairs analysis. Surg Endosc. 2017;31:4126-30.

18. Chen PD, Wu CY, Hu RH, Chou WH, Lai HS, Liang JT, et al. Robotic versus open hepatectomy for hepatocellular carcinoma: a matched comparison. Ann Surg Oncol. 2017;24:1021-8.

19. Abitbol J, Cohn R, Hunter S, Rombaldi M, Cohen E, Kessous R, et al. Minimizing pain medication use and its associated costs following robotic surgery. Gynecol Oncol. 2017;144:187-92.

20. Epstein AJ, Groeneveld PW, Harhay MO, Yang F, Polsky D. Impact of minimally invasive surgery on medical spending and employee absenteeism. JAMA Surg. 2013;148:641-7.

21. Martin BC, Fan MY, Edlund MJ, Devries A, Braden JB, Sullivan MD. Long-term chronic opioid therapy discontinuation rates from the TROUP study. J Gen Intern Med. 2011;26:1450-7.

22. Alam A, Gomes T, Zheng H, Mamdani MM, Juurlink DN, Bell CM. Long-term analgesic use after low-risk surgery: a retrospective cohort study. Arch Intern Med. 2012;172:425-30.
23. Schoenfeld AJ, Belmont PJ Jr, Blucher JA, Jiang W, Chaudhary MA, Koehlmoos $\mathrm{T}$, et al. Sustained preoperative opioid use is a predictor of continued use following spine surgery. J Bone Joint Surg Am. 2018;100:914-21.

24. Schoenfeld AJ, Nwosu K, Jiang W, Yau AL, Chaudhary MA, Scully RE, et al. Risk factors for prolonged opioid use following spine surgery, and the association with surgical intensity, among opioid-naive patients. J Bone Joint Surg Am. 2017;99:1247-52.

25. Chaudhary MA, Scully R, Jiang W, Chowdhury R, Zogg CK, Sharma M, et al. Patterns of use and factors associated with early discontinuation of opioids following major trauma. Am J Surg. 2017;214:792-7.

26. Harrison LM, Kastin AJ, Zadina JE. Opiate tolerance and dependence: receptors, G-proteins, and antiopiates. Peptides. 1998;19:1603-30.

27. Evans CJ, Cahill CM. Neurobiology of opioid dependence in creating addiction vulnerability. F1000Research. 2016;5:F1000 Faculty Rev-1748.

28. Bailey CP, Husbands SM. Novel approaches for the treatment of psychostimulant and opioid abuse - focus on opioid receptor-based therapies. Expert Opin Drug Discovery. 2014;9:1333-44.

29. Piazza PV, Deroche-Gamonet V. A multistep general theory of transition to addiction. Psychopharmacology. 2013;229:387-413.

30. Stark N, Kerr S, Stevens J. Prevalence and predictors of persistent postsurgical opioid use: a prospective observational cohort study. Anaesth Intensive Care. 2017:45:700-6.

31. Shah A, Hayes CJ, Martin BC. Characteristics of initial prescription episodes and likelihood of long-term opioid use - United States, 2006-2015. MMWR Morb Mortal Wkly Rep. 2017;66:265-9.

32. Sullivan MD, Ballantyne JC. What are we treating with long-term opioid therapy? Arch Intern Med. 2012;172:433-4.

33. Wunsch $H$, Wijeysundera DN, Passarella MA, Neuman MD. Opioids prescribed after low-risk surgical procedures in the United States, 20042012. JAMA. 2016;315:1654-7.

34. Brennan F, Carr DB, Cousins M. Pain management: a fundamental human right. Anesth Analg. 2007;105:205-21.

35. Chou R, Gordon DB, de Leon-Casasola OA, Rosenberg JM, Bickler S, Brennan T, et al. Management of postoperative pain: a clinical practice guideline from the American pain society, the American Society of Regional Anesthesia and Pain Medicine, and the American Society of Anesthesiologists' Committee on Regional Anesthesia, Executive Committee, and Administrative Council. J Pain. 2016;17:131-57.

36. Joshi GP, Jaschinski T, Bonnet F, Kehlet H, P. collaboration. Optimal pain management for radical prostatectomy surgery: what is the evidence? BMC Anesthesiol. 2015;15:159

37. Patel HD, Srivastava A, Patel ND, Faisal FA, Ludwig W, Joice GA, et al. A prospective cohort study of postdischarge opioid practices after radical prostatectomy: the ORIOLES initiative. Eur Urol. 2019;75(2):215-8.

38. Solouki S, Plummer M, Agalliu I, Abraham N. Opioid prescribing practices and medication use following urogynecological surgery. Neurourol Urodyn. 2019;38:363-8.

39. Howard R, Fry B, Gunaseelan V, et al. Association of opioid prescribing with opioid consumption after surgery in michigan. JAMA Surg. 2018;154:e184234.

40. Hansen L. The Truven health MarketScan databases for life sciences researchers. Ann Arbor: Truven Health Analytics; 2017.

41. LV L, Shao Y-F, Zhou Y-B. The enhanced recovery after surgery (ERAS) pathway for patients undergoing colorectal surgery: an update of metaanalysis of randomized controlled trials. Int J Color Dis. 2012;27:1549-54

\section{Publisher's Note}

Springer Nature remains neutral with regard to jurisdictional claims in published maps and institutional affiliations. 